\title{
A UTILIZAÇĀO DOS PERIÓDICOS NA BIBLIOTECA DA ESCOLA DE ENFERMAGEM DA USP
}

\author{
Carmen Sylvia Arantes Leal Aguiari*
} Maria Mariko Nishimoto Hondo**

AGUIARI, C. S. A. L. \& HONDO, M. M. N. A utilização dos periódicos na Biblioteca da Escola de Enfermagem da USP. Rev. Esc. Enf. USP, Sào Paulo, 16(1): $5-16,1982$.

A seleção, aquisição e o espaço para guarda das coleçōes de periódicos trazem problemas para as bibliotecas. As autoras examinam os titulos de periódicos adquiridos por compra, doação e permuta pela Biblioteca da Escola de Enfermagem da Universidade de São Paulo. Tendo em vista o grande número de periódicos, seu custo $e$ escassez de verbas, desenvolve um estudo com os objetivos de: identificar os titulos de periódicos mais consultados pelos usuários da Biblioteca em 1981, e a lingua em que são publicados; verificar a forma de aquisição desses titulos. Os resultados obtidos são apresentados em Tabelas e Gráficos as quais mostram um número elevado de consultas em lingua portuguesa, apesar do número reduzido de titulos; também apontam um grande número de consultas nos periódicos adquiridos por doação. $O$ estudo inclui recomendação sobre a aquisição de periódicos.

\section{INTRODUÇAOO}

O periódico científico é sobremaneira o material bibliográfico mais importante no acervo de uma biblioteca universitária dada a sua contribuição efetiva tanto para o ensino como para a pesquisa.

Constitui por um lado, veículo de comunicação eficiente entre os profissionais e, por outro, material de rápida expansão.

A seleção, aquisição e guarda das coleções de periódicos acarretam problemas para as bibliotecas.

Quanto à seleção, temos que considerar os títulos adquiridos por permuta, doação e compra. Os selecionados por permuta e doação em geral são provenientes de instituições públicas ou privadas, nacionais ou internacionais, que editam periódicos. Em nosso caso, oferecemos por permuta a publicação oficial da Escola que é a Revista da Escola de Enfermagem da USP.

Os títulos de periódicos norte-americanos em enfermagem, em geral são da responsabilidade de associações específicas (ex.: Enfermagem em Centro Cirúrgico) que entregam os originais para serem publicados por firmas comerciais. Essas se encarregam de uma tiragem controlada e de sua expedição.

* Professor Assistente dn Departamento de Ortentação Profissional da Escola de Enfermagem da USP - disciplina Orientação Bibliográfica. Mestre em Ciências da Comunicação. Bibliotecária - Chefe de Biblioteca da Escola de Enfermagem da USP.

* Bibliotecária de Referência e periódicos da Biblioteca da Escola de Enfermagem da USP. 
As permutas da Revista da Escola de Enfermagem da USP com determinados títulos estrangeiros duram, em média, o prazo de 3 anos, talvez em razão da firma estrangeira ser empresa que recebem pagamento pela propaganda comercial, possuem equipes que revisam e propagam a diagramação do conteúdo, obedecendo também a uma periodicidade rigida.

Os títulos que esta Biblioteca seleciona inicialmente são por permuta, e, em pouco tempo passam a ser obtidos por compra.

Os títulos de Enfermagem nacionais são, em geral, editados por associações de profissionais que os elaboram, revisam na integra o conteúdo e as provas, sendo que às gráticas somente se responsabilizam pela impressão, por outro lado, são desfavorecidas de auxílios de propaganda, pois a tiragem é pequena e a periodicidade irregular e a longos intervalos.

Com relação à permuta, os periódicos nacionais em Enfermagem têm boa aceitação no estrangeiro, principalmente quando possuem resumo em inglês, os quais são indexados em diretórios e em índices bibliográficos da área em pauta.

Os periódicos selecionados por compra, tanto nacionais como internacionais, não causam grandes problemas. São adquiridos por meio de diferentes tipos de remessa financeira, em moeda nacional. Os titulos de periódicos internacionais podem, em geral, ser adquiridos diretamente um a um das próprias editoras, ou indiretamente por meio de listagens enviadas às agências especializadas que facilitam em grande parte o trabalho das bibliotecas.

No processo de seleção e aquisição dos periódicos, devemos levar em conta o espaço nas estantes, a ser reservado para armazenar adequadamente este material.

Devemos lembrar, também, da encadernação, um procedimento dispendioso e necessário, que impede a perda de números avulsos e também facilita a guarda. Neste item devemos optar por uma encadernação mais resistente para os periódicos que são manuseados constantemente e uma encadernação inferior para os que são menos consultados.

Devemos ainda, considerar, a realidade de que as verbas disponiveis são sempre escassas. Dentro da problemática verba para aquisição, preparo técnico, conservação, temos que nos valer de dados estatísticos, para futuras tomadas de medidas administrativas.

$\mathrm{Na}$ revisão bibliográfica do tema, STEWART ${ }^{8}$ informa que o melhor meio para medir a importância de um periódico numa biblioteca é o uso dele feito pelos usuários.

ANDRADE et alii ${ }^{2}$ elaboraram um trabalho numa biblioteca especializada em Saúde Pública, utilizando a metodologia de Bradford para relacionar um determinado número de periódicos mais consultados pelos 
usuários daquela unidade. Aliaram também, nesse estudo, fórmulas estatísticas para alcançar outros objetivos.

BUCHMANN et alii * planejaram um estudo para avaliar a coleção de periódicos do Centro de Processamento de Dados em Ciência da Computação; e RANGEL et alii ${ }^{7}$ apresentaram um estudo também para avaliar a circulação de periódicos visando a utilização pelos usuários locais.

Temos observado que existe preocupação crescente dos bibliotecários das diversas áreas em elaborarem estudos, para determinar um núcleo representativo de periódicos, e outros para avaliar a utilização dos mesmos pelos usuários nas diversas instituições.

No Brasil a metodologia de BRADFORD ${ }^{3}$ foi aplicada em várias áreas; entre essas citamos algumas como Física, Botânica, Biologia, Geologia, Microbiologia-Imunologia-Parasitologia e Enfermagem.

Na Enfermagem tal metodologia foi aplicada por AGUIARI ${ }^{1}$, que se baseou nos programas das disciplinas ministradas no Curso de Enfermagem e Obstetricia. Os dados para o estudo foram retirados da obra INTERNATIONAL NURSING INDEX ${ }^{6}$. O estudo apontou o número de títulos de periódicos mais significativos para aquelas disciplinas.

Afim de completar o estudo acima referido, planejamos outro baseado nas consultas dos usuários da Biblioteca da Escola de Enfermagem da USP, com a finalidade de tentar solucionar alguns dos muitos problemas relacionados à aquisição dos periódicos.

São seus objetivos:

- identificar os títulos de periódicos mais consultados pelos usuários da Biblioteca e a língua em que são publicados;

- verificar a forma de aquisição desses títulos.

\section{METODOLOGIA}

\section{Caracteristicas da Unidade}

O presente trabalho foi realizado na Biblioteca da Escola de Enfermagem da USP, onde são ministrados os seguintes cursos:

- tronco profissional comum, Habilitação em Enfermagem MédicoCirúrgica e Habilitação em Enfermagem Obstétrica, do curso de graduação em Enfermagem e Obstetrícia;

- Pós-graduação em nível de Mestrado e nível de Doutorado.

Além desses, é ministrada a disciplina Prática de Ensino de Enfermagem para alunos do curso de Licenciatura da Faculdade de Educação da USP. 
A Biblioteca é universitária, especializada, centralizada, cujo acervo de periódicos está diretamente voltado para às disciplinas dos diversos cursos ministrados na Unidade.

A Biblioteca funciona diariamente, no horário de $7 \mathrm{~h}$ a $21 \mathrm{~h}$ e aos sábados de $7 \mathrm{~h} 30 \mathrm{~min}$ às $12 \mathrm{~h} 30 \mathrm{~min}$.

Atende ao seguinte público: docentes, alunos e pessoal administrativo da própria Escola e de outras escolas universitárias bem como a clientela externa que localiza as obras de seu interesse nos catálogos coletivos localizados na Biblioteca Central da USP, ou publicados e distribuidos às Unidades de ensino da Universidade e a outras entidades.

Os títulos de periódicos a serem adquiridos são selecionados e apontados pelos docentes e aprovados pela Comissão de Biblioteca e Publicações. O número de periódicos correntes em 1981 atingia o total de 178 titulos, dos quais 87 por compra, 59 por permuta e 32 por doação. Desses 178 títulos existentes, 95 em inglês, 66 em português, $12 \mathrm{em}$ espanhol, 3 em francês, 1 um japonês e 1 em italiano.

A coleção de periódicos e as obras de referência são separadas dos livros, em sala própria, na Biblioteca, que além de estantes, mesas, cadeiras, conta com fichários; os periódicos são ordenados nas estantes por ordem alfabética de títulos. Os leitores consultam os fichários e localizam nas estantes o material desejado para consulta. Sobre as mesas de consulta são colocadas diariamente blocos de fichas para serem preenchidas pelos leitores, referentes ao material consultado. Essas fichas contém identificação do periódico consultado (anexo 1). Há um bibliotecário de plantão nesta sala, que orienta adequadamente os leitores nesta etapa.

\section{Universo do estudo}

Foram universo do estudo todos os títulos de periódicos e publicações seriadas consultados e ou xerocopiados pelos usuários da Biblioteca da Escola de Enfermagem da USP.

Excluimos desse estudo os empréstimos entre biblioteca solicitados e atendidos, pois acreditamos que esses resultam de títulos de outras áreas utilizados pelos estudiosos para fundamentar seus trabalhos na área da Enfermagem, ou vice-versa.

Retiramos também deste, o empréstimo domiciliar visto ser por um prazo restrito.

\section{Periodo}

O estudo abrangeu o período correspondente de 2 de janeiro a 31 de dezembro de 1981. Achamos conveniente incluir nesse estudo, os periodos de férias escolares, bem como a semana santa e a da Pátria, 
pois supomos que sejam periodos representativos; os consulentes se aproveitam deles para dar andamento nas pesquisas, projetos e outros trabalhos acadêmicos.

\section{Levantadementos de dados}

Foram instrumento de pesquisa inicialmente utilizado as fichas deixadas nas mesas de consulta. Essas são preenchidas individualmente pelos usuários (anexo 1), após as consultas efetuadas nos diferentes periódicos; no fim do dia esses dados, por sua vez, são transportados pelo bibliotecário de plantão para as folhas do anexo 2 .

\section{Apuração dos dados}

As folhas de estatística diária (anexo 2) são agrupadas em ordem alfabética dos títulos dos periódicos, em pastas com divisionárias correspondentes aos meses do ano. sultado.

No fim de cada mês, são apurados o total de cada periódico con-

A partir dos resultados mensais das fichas, chegamos à estatística anual. As fichas são posteriormente ordenadas por ordem descrescente do número de consultas.

Com a finalidade de indicar o percentual de utilização de um determinado título de periódico aplicamos a fórmula, adotadas por FERREIRA et alii ${ }^{5}$ :

$\frac{\text { Número de consulta por título } \times 100}{\text { Número total de consultas dos periódicos no ano }}$

A fórmula acima, foi aplicada a partir do total anual das fichas de todos os títulos de periódicos consultados na Biblioteca que está contida no denominador.

Os dados das fichas já ordenados por ordem decrescente de consultas são transportados para uma tabela (tabela 1). Estes dados foram agrupados por diferentes formas de aquisição (compra, doação, permuta) . A seguir os mesmos dados foram distribuídos pelas línguas de publicação dos periódicos, e, transportados para a tabela 2 .

Para cada forma de aquisiçāo calculamos a porcentagem dos títulos consultados em relação ao número total dos títulos existentes. $\mathrm{O}$ número de consultas de periódicos de cada idioma foi igualmente calculado em relação ao número total de consultas em todos os idiomas.

Foi também calculada a porcentagem de consultas de periódicos por forma de aquisoção bem como por idioma (tabela 2). 


\section{RESULTADOS E COMENTARIOS}

De acordo com as tabelas 1 e 2, verificamos o seguinte:

- Quanto aos periódicos mais consultados:

Na tabela 1 aparece em primeiro lugar o periódico REVISTA BRASILEIRA DE ENFERMAGEM, publicação oficial da Associação Brasileira de Enfermagem; os docentes em sua maioria como membros da citada entidade a recebem graciosamente. Em segundo lugar a REVISTA DA ESCOLA DE ENFERMAGEM DA USP, publicação oficial da Escola de Enfermagem da USP, os docentes em sua maioria assinam o referido periódico. Portanto o índice mais alto de consultas desses periódicos na Biblioteca recai naturalmente entre os discentes e outros leitores. Os títulos apontados (tabela 1) $\mathrm{n}^{\circ} 6$ (THE AMERICAN JOURNAL OF NURSING), $\mathrm{n}^{\circ} 7$ (NURSING TIMES), $\mathrm{n}^{\circ} 9$ (NURSING MIRROR), sobre número de consultas, coincidem com os resultados obtidos no estudo elaborado por AGUIARI 1, (1980), cujo objetivo foi relacionar os periódicos mais utilizados no estudo das disciplinas do curso de graduação em Enfermagem e Obstetrícia no Brasil. Para esse utilizou a metodologia de BRADFORD ${ }^{3}$, que diz respeito ao assunto dos artigos. No presente estudo utilizamos uma fórmula estatística de consultas e os títulos citados acima também apresentaram um alto índice de consultas.

- Quanto a forma de aquisição:

Dos 178 periódicos existentes foram consultados $61 \%$ (tabela 1); dos 87 comprados, $74 \%$; dos 32 doados, $87 \%$; e, dos 59 permutados, $25 \%$, (tabela 2). Talvez o baixo índice de consultas dos periódicos permutados seja por eles estarem distantes dos interesses dos usuários.

- Quanto ao idioma de publicação:

Dos títulos adquiridos sob diferentes formas em diversas línguas, os mais consultados (respectivamente $90,47 \%$ e $100 \%$ ) foram naturalmente os publicados em língua portuguesa (tabela 2). Tudo nos leva a crer que os leitores inicialmente procuram a informação desejada em língua portuguesa não o conseguindo fazem a opção por outras línguas das quais o inglês, é aquela em que existe mais informação.

- Nota: Cabe aqui uma observação quanto à periodicidade das publicações:

Os periódicos publicados em língua inglesa são em geral, de periodicidade curta (mensal ou semanal) e de grande tiragem, contendo, em sua maioria, artigos com poucas laudas, ilustrações e muita propaganda comercial. Esse resultado deverá ser analisado pelos editores das revistas nacionais em Enfermagem, pois estas publicam artigos extensos, são de periodicidade ampla e tiragem pequena, o que dificulta $o$ interesse das agências de propaganda. 


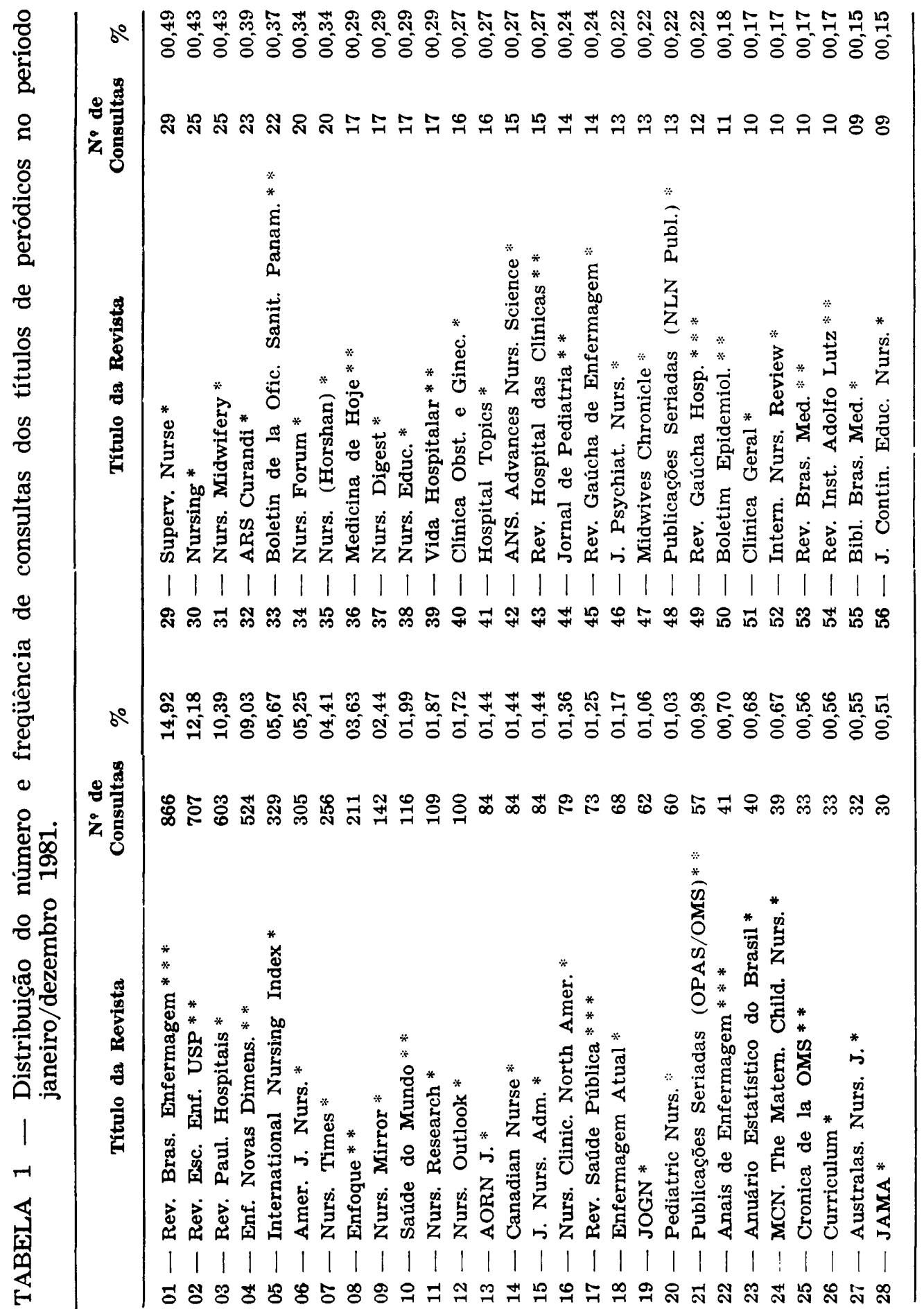




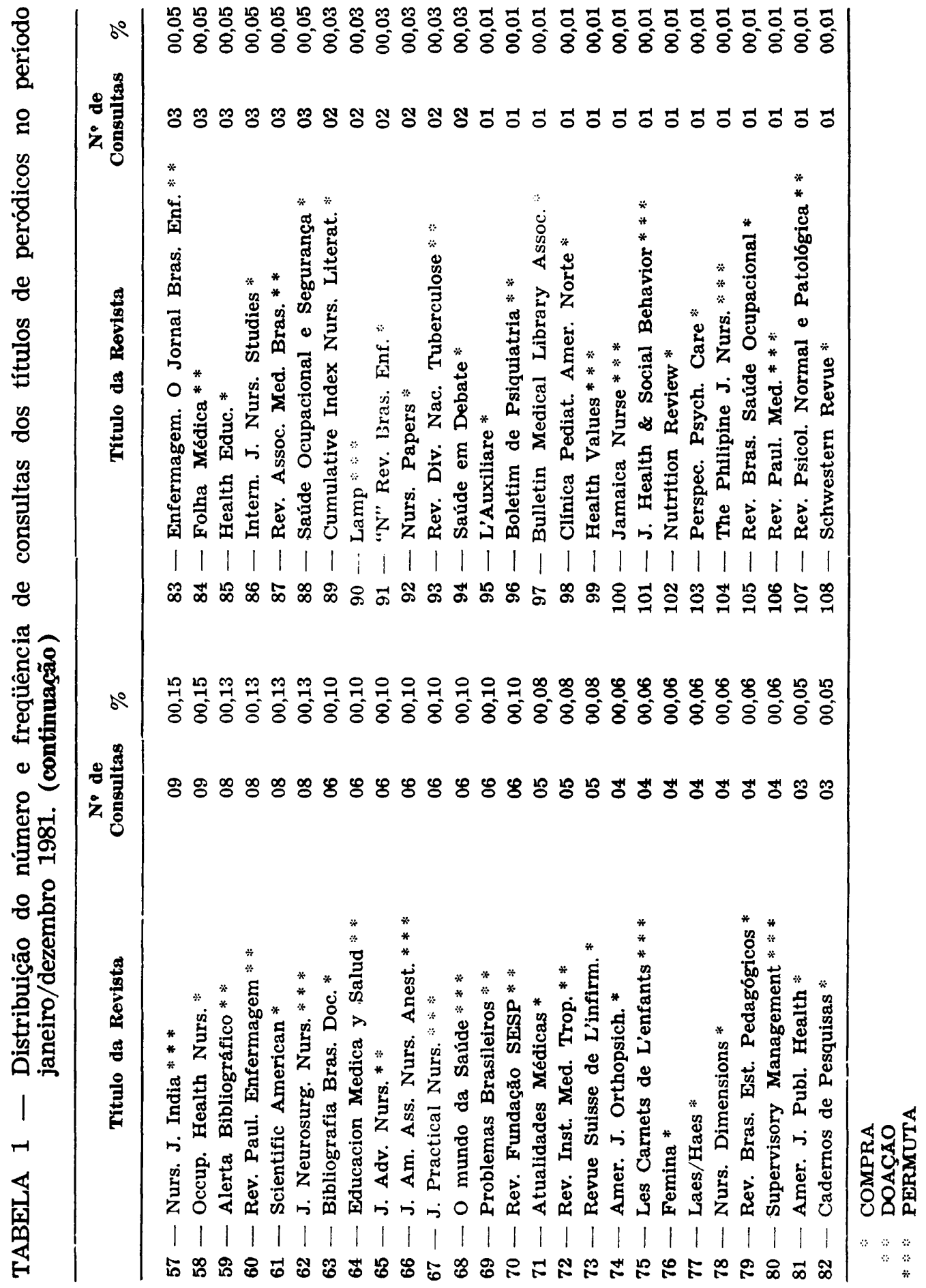




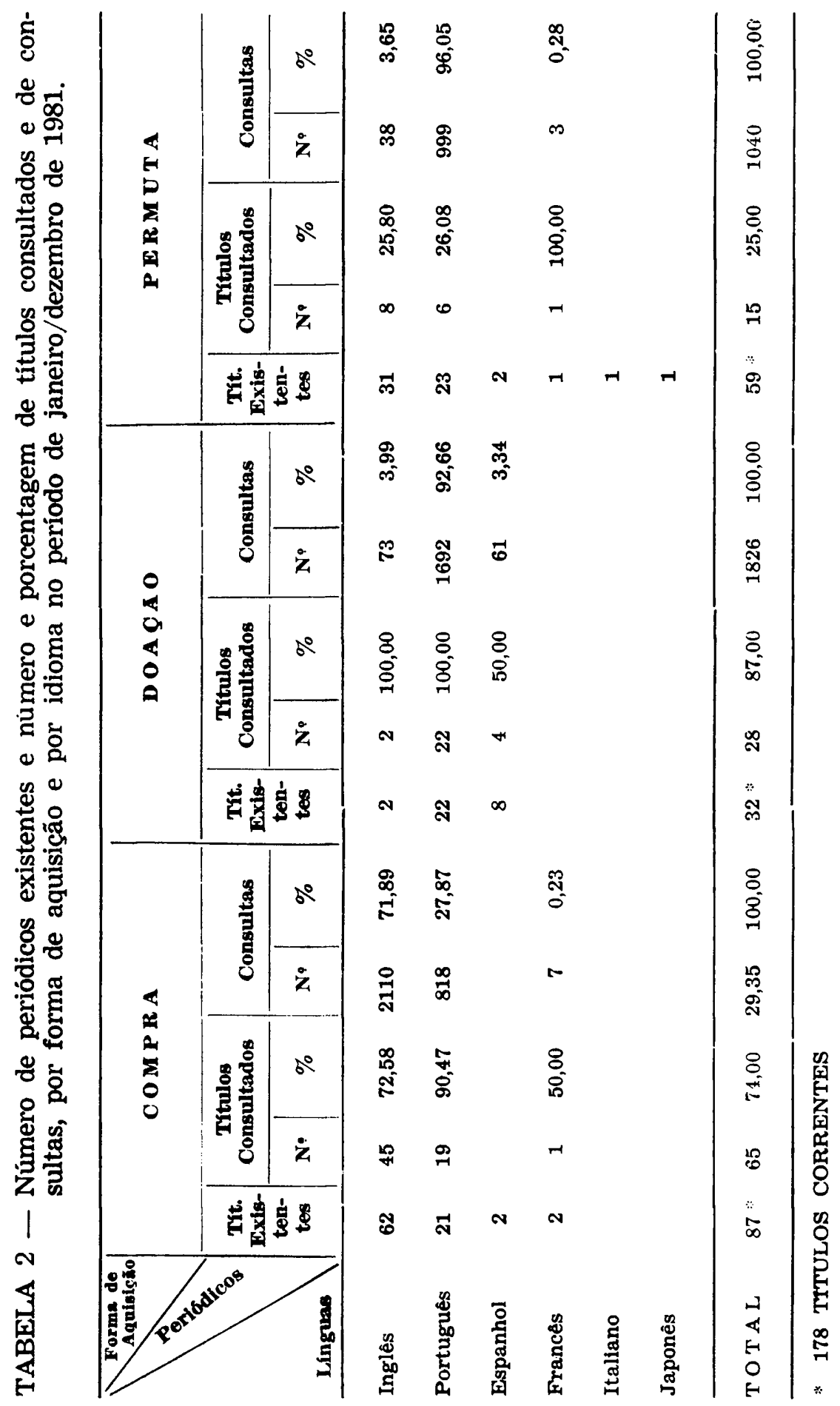




\section{CONCLUSÕES E RECOMENDAÇOEES}

Os objetivos inicialmente propostos neste estudo foram atingidos, e trouxeram subsídios valiosos para o planejamento racional da aquisição de periódicos.

As obras mais consultadas foram, naturalmente, as escritas em língua portuguesa.

Quanto a forma de aquisição, as mais consultadas foram as obtidas por compra, por serem em maior número, seguidas das obtidas por doação.

Recomendamos às Escolas de Enfermagem que procurem obter as publicações distribuidas gratuitamente por entidades nacionais e internacionais pois, em geral, elas são de grande interesse para o ensino.

Acreditamos que serão de utilidade estudos ulteriores em continuidade a este.

Acreditamos, também, na conveniência, da realização de estudos outros, tais como:

- categorias dos consulentes;

- os assuntos mais procurados;

- número de consultas de determinados periódicos através do tempo (por exemplo nos últimos 5 anos, comparados aos 5 anos anteriores);

- títulos de periódicos apontados nas referências bibliográficas dos trabalhos publicados, teses, projetos de pesquisa e monografias sobre Enfermagem.

Com tais estudos provavelmente, teremos uma lista dos periódicos, mais úteis para a consecução dos objetivos do ensino e da pesquisa.

AGUIARI, C. S. A. L. \& HONDO, M. M. N. The utilization of the periodical in the library the University of São Paulo School of Nursing. Rev. Esc. Enf. USP, São Paulo, 16(1):5-16, 1982.

Selection, acquisition and space for storage of periodicals' collection, bring problems to the libraries. Considerations are made about the periodicals' titles acquired by buying, donation and exchange. Taking into consideration the great number of titles that already exist and the scarce budget, a study was made on the consulting of periodicals at the Library of the University São Paulo School of Nursing. Its objetives were: to identify the title of the most consulted periodicals in 1981; and the idiom in which they are published; how they were obteined. The findings, presented in Tables and Graphs, show that, as expected, the most consulted periodicals are the ones published in Portuguese, although they are in much lesser numbers. They also show a large number of consultations of the donated periodicals. The study includes a recommendation on the acquisition of periodicals. 


\title{
REFERENCIAS BIBLIOGRÅFICAS
}

1 - AGUIARI, C. S. A. L. Lista básica de periódicos para o curso de graduação em enfermagem e obstetricia no Brasil: estudo bibliométrico, 1966-1976. São Paulo, 1980. (Dissertação de Mestrado - Escola de Comunicações e Artes da USP).

2 - ANDRADE, M. T. D. et alii. Avaliação do uso de periódicos em biblioteca especializada em Saúde Pública. Rev. Saúde públ., São Paulo, 12(3):388-402, set. 1978.

3 - BRADFord, S. C. O caos documentário. In: Documentação. São Paulo, Fundo de Cultura, 1961. cap. 9, p. 198-216.

4 - BUCHMANN, M. C. S. et alii. Avaliação da coleção de periódicos correntes da biblioteca do Centro de Processamento de Dados Pós-Graduação em Ciências da Computação (CPD/PGCC) da UFRS: metcdulogia e resultados. Kev. Bras. Bibliotecon. Doc., São Paulo, 14(3/4):160-173, jul./dez. 1981.

5 - Ferreira, G. I. et alii. Problemas de coleta $\epsilon$ utilização de dados estatísticos em bibliotecas. Boletim ABDF, Brusília, 3(4):21-5, out./dez, 1980.

6 - INTERNATIONAL NURSING INDEX: annual cumulation. New York, American Journal of Nursing, 1966.

7 - RANGEL, M. E. et alii. Avaliação da circulação de periódicos: uma análise do atendimento prestado aos usuários locais. Rev. Bras. Bibliotecon. Doc., São Paulo, 14(1/3): 33-46, jan./jun. 1981 .

R - STEWART, B. Periodicals and the liberal arts college library. Coll. Res. Libr., Chicago, $36: 371-8,1975$.

\author{
ANEXO 1 \\ IDENTIFICAÇÃO DO PERIÓDICO CONSULTADO
}

Título do Periódico:

Ano:

Vol.:

$N^{\prime}$ 


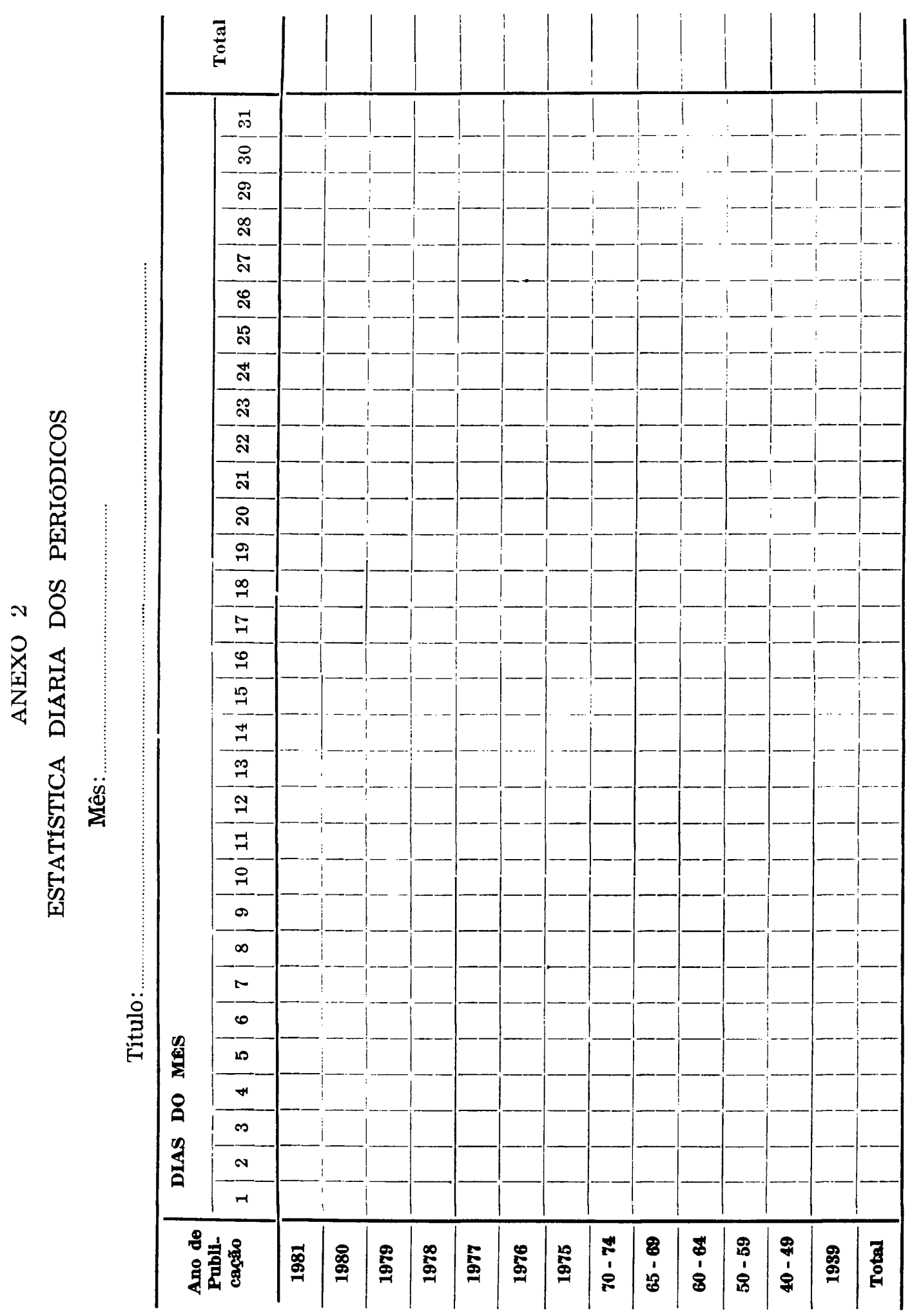

